\title{
Eating behaviour and eating disorders in students of nutrition sciences
}

\author{
Anne Korinth, Sonja Schiess and Joachim Westenhoefer* \\ Public Health Research Group, Faculty of Life Sciences, University of Applied Sciences Hamburg, Lohbruegger \\ Kirchstr. 65, 21033 Hamburg, Germany
}

Submitted 14 January 2008: Accepted 31 March 2009: First published online 12 May 2009

\begin{abstract}
Objective: Sometimes the suspicion is put forward that nutrition students show more disordered eating patterns, which may be among the motivating factors to study nutrition. At the same time, it is not clear whether the students' increasing knowledge about diet and nutrition is associated with a more healthy eating behaviour or with an unhealthy obsession with food choices.

Design: Cross-sectional comparison of nutrition students from German universities during the first year of their studies $(n$ 123) and during higher semesters ( $n$ 96), with a control group from other study programmes ( $n 68$ and $n$ 46, respectively). Dietary restraint, disinhibition, the tendency towards orthorexia nervosa and healthy food choices were assessed using a questionnaire.

Results: Nutrition students showed higher levels of dietary restraint than the control group. Disinhibition and orthorexia nervosa did not differ between nutrition students and controls. Orthorexic tendencies were lower in the more advanced nutrition students. Healthy food choices did not differ among students in the first year. More advanced nutrition students showed healthier food choices, whereas the corresponding controls showed slightly more unhealthy food choices. Conclusions: Nutrition students, more than other students, tend to restrict their food intake in order to control their weight, but they do not have more disturbed or disordered eating patterns than other students. Moreover, during the course of their studies, they adopt slightly more healthy food choices and decrease their tendency to be obsessive in their eating behaviour.
\end{abstract}

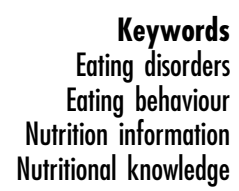

Strategies of health promotion and health education often focus on providing information and knowledge to the consumer, particularly with regard to diet and nutrition. The aim of providing information and knowledge is to enable the consumer to make informed choices, and obviously it is hoped that the informed choices will be healthier choices. For example, the recent European Commission white paper on a strategy for Europe on Nutrition, Overweight and Obesity ${ }^{(1)}$ states that 'only the well-informed consumer is able to make rational decisions' (p. 3). Nevertheless, the role of knowledge and information in controlling dietary behaviours may be rather limited. Several studies have documented that there are only poor relationships between nutrition knowledge on the one hand, and attitudes about foods or consumption of foods on the other hand ${ }^{(2-5)}$. French children, for example, were able to list healthy foods, but nevertheless, the most preferred foods were foods which are high in sugar and/or fat ${ }^{(6)}$. Another study found that nutrition knowledge was not correlated with the BMI in patients from a general practice ${ }^{(7)}$. However, other studies reported positive associations between nutrition knowledge and food consumption as well ${ }^{(8,9)}$. The limited relationship between nutrition knowledge and food intake may be explained by the finding that attitudes to foods are dependent on several evaluative bases, among which health evaluations are only one; and that nutrition knowledge moderates the relationship between health evaluations of foods and general attitudes towards foods: in subjects with better knowledge, health evaluations influenced attitudes to foods more strongly than in subjects with poorer knowledge ${ }^{(10)}$.

Attempts to make people more aware of their food intakes and increase their nutritional knowledge might also have undesirable effects in subgroups of the population. During recent years, the description of a new eating disorder, orthorexia nervosa, has been proposed ${ }^{(11)}$. The defining feature of this disorder is an obsession with eating healthy food and avoiding unhealthy food. This description of an eating disorder is far from being a commonly accepted diagnostic category. Nevertheless, it has initiated some preliminary work, examining this idea in more 
detail $^{(12,13)}$. A recent survey of dietitians in Austria found that among dietitians, a considerable portion of $12 \cdot 8 \%$ showed four or more symptoms of orthorexia nervosa ${ }^{(14)}$. In addition, dietitians showing signs of orthorexia nervosa also reported, more often, the existence of a previous or concurrent eating disorder like anorexia nervosa, bulimia nervosa or binge eating disorder. This finding is in line with the suspicion and belief that is sometimes brought forward: students of nutrition and dietetics could start their studies with the motivation to deal with their own dietary problems and disordered eating patterns. However, even if a higher rate of obsessive-compulsive healthy eating patterns and/or eating disorders in dietitians and nutritionists would be confirmed, several explanations for this can be considered. The disordered attitudinal and behavioural patterns could be a pre-existing motivation to start a corresponding study programme, or the disordered eating behaviour could be the result of an exaggerated preoccupation with healthy diet that is produced, or at least intensified, during the course of the study programme. The latter possibility would have important implications for health and nutrition education programmes. Not only could such programmes have only limited influence on healthy eating as discussed above, they could also induce or promote patterns of disordered eating in a portion of their subjects.

This possibly dangerous pathway has a well-known parallel in the field of weight control and eating disorders. In the 1970s, Peter Herman and his colleagues introduced the notion of restrained eating ${ }^{(15,16)}$, which has been defined as an intention to restrict food intake in order to reduce weight or to prevent weight gain. Obviously, this intention is of central importance in the treatment and prevention of overweight and obesity. Since that time, dietary restraint has received much more attention as a potential risk factor; probably the most important risk factor for the development of eating disorders like bulimia nervosa or binge eating disorder ${ }^{(17-19)}$. Cognitive behavioural therapy, which aims at reducing dysfunctional dietary restraint, has been shown to be effective in the treatment of these eating disorders ${ }^{(19,20)}$.

However, the role of dietary restraint in the prevention and treatment of obesity on the one hand, and in the development and maintenance of eating disorders on the other, appears to be more complicated. It has been shown that two different subcomponents of dietary restraint may be distinguished: flexible control of eating behaviour and rigid control of eating behaviour ${ }^{(21,22)}$. Flexible restraint has been associated with lower BMI, better long-term weight reduction and weight maintenance and a lower tendency to overeating, whereas rigid restraint has been associated with an increased tendency to overeating, poorer weight control and higher $\mathrm{BMI}^{(21-25)}$. Therefore, dietary restraint per se should not be considered as an indicator or precursor of disordered eating. Only the rigid restraint component seems to be part of eating disorders, whereas flexible restraint seems to be useful for successful weight management and may be considered as a component of healthy eating patterns.

On this background, the disordered eating patterns which are addressed in the present paper as potential consequences of an increased preoccupation with healthy diet and nutrition, comprise: (i) obsessive-compulsive patterns of thinking and behaviour related to food intake (orthorexia) and/or (ii) the tendency to overeat and experience feelings of loss of control over eating (disinhibition of control) which is a key feature of eating binges ${ }^{(26)}$.

We chose to examine university students of nutritional sciences because we could not imagine a subgroup of the population that acquires more knowledge of nutrition within a couple of years. Thus, we expected that if the increased preoccupation with healthy diet and the improved nutritional knowledge have any effects, these should be most clearly present in nutrition students.

Based on this background, the aim of the present study was to examine: (i) whether students of nutrition differ from other students in the extent of disordered eating patterns; (ii) whether the extent of such disordered eating patterns changes during the course of the study programme; and (iii) whether students of nutrition improve healthy food choices in parallel to their increasing knowledge of nutrition.

\section{Methods}

\section{Sample and procedure}

Subjects were recruited from a number of different universities in Germany. Students of nutrition or nutrition and home economics were recruited at the Hamburg University of Applied Sciences, the University of Giessen, the University of Potsdam and the University of Kiel. As a control group, students of educational sciences at the University of Potsdam, as well as students from a number of different study programmes of design and engineering at the Hamburg University of Applied Sciences were recruited. These study programmes were chosen because - with the exception of engineering - the portion of female students is comparable to the nutrition programmes. Students were approached on the campuses during the lectures or in the breaks between lectures, and asked for their voluntary participation. Students were included in the study if they were either in the first two semesters of their study programme or in the seventh semester or higher (DiplomaProgrammes in Germany from which subjects were recruited usually last at least eight semesters) in order to compare freshmen and more advanced students.

\section{Measures}

The questionnaire consisted of four parts: (i) basic personal characteristics like age, gender, study programme and semester; (ii) the items of the dietary restraint scale 
and the disinhibition scale from the Eating Behaviour Questionnaire $^{(27)}$, which is a German adaptation of the Three-factor Eating Questionnaire (TFEQ) ${ }^{(28)}$; (iii) the German translation $^{(14)}$ of ten items to measure orthorexic behaviours which were originally proposed by Bratman ${ }^{(11)}$; and (iv) a short FFQ which comprised twenty-one food groups.

The TFEQ is a widely used instrument to assess eating behaviour in clinical as well as general population settings. The dietary restraint scale assesses the tendency to restrict food intake in order to lose weight or to prevent weight gain. As mentioned in the introduction, dietary restraint has been considered as a major risk factor for eating disorders. However, this view has been questioned and the distinction between the flexible and rigid control components of restraint has been suggested as an important improvement. The items of the restraint scale also allow the computation of the short forms of the flexible and rigid control scales ${ }^{(21)}$. The disinhibition scale reflects the tendency to overeat as a consequence of environmental or emotional stimuli. This tendency includes the breakdown of cognitive control of eating behaviour and dietary restraint. This disinhibition of control is closely related to episodes of binge eating and indeed, patients with Bulimia nervosa or Binge Eating Disorder have significantly higher scores of disinhibition than healthy controls ${ }^{(29,30)}$. Therefore, the disinhibition scale of the TFEQ is an appropriate measure of disordered eating patterns. The orthorexia scale has been proposed to assess the tendency towards an obsession with eating more or less exclusively healthy food and avoiding unhealthy food, and therefore also indicates a special type of disordered eating behaviour pattern. The FFQ has been included in order to evaluate healthy dietary intakes.

The dietary restraint and the disinhibition scale were evaluated using the standard scoring schemes ${ }^{(27,28)}$, while the rigid and flexible control subscales were evaluated according to the proposal by Westenhoefer et $a l^{(21)}$. For the orthorexia scale, a score was computed by counting the positive answers to the ten questions. For the FFQ, we developed a scoring scheme ranging from 0 to 12, where higher scores indicate a better match of self-reported intake of food groups with current dietary recommendations, and thus a more healthy food choice ${ }^{(31)}$.

\section{Statistical analysis}

BMI was computed from self-reported weight and height $\left(\mathrm{kg} / \mathrm{m}^{2}\right)$. Descriptive statistics are presented as means and SD. Gender distribution was tested for differences between nutrition students and the control group using a $\chi^{2}$ test. Differences of the average scores from the questionnaires, age and BMI were analysed using a twofactorial ANOVA with nutrition $v$. control students as the first factor, and first/second semester $v$. seventh and higher semester as the second factor. The significance level was set to $\alpha=0 \cdot 05$.

\section{Results}

\section{Sample characteristics}

In all, 219 students of nutrition or nutrition and home economics were recruited - 195 females (89\%) and twenty-four males (11\%); 123 students (56\%) were freshmen (first or second semester) and the remaining ninety-six students were from the seventh semester or higher. The control group consisted of 114 students - ninety-nine females (87\%) and fifteen males (13\%); sixty-eight students (60\%) were freshmen and forty-six were from the seventh semester or higher. The average ages were 22.5 (SD 3.1) years for the first/second semester students, and $25 \cdot 7$ (SD 3.5) years for the higher semester groups (nutrition students and control group pooled). The average BMI in the total sample was $21 \cdot 6(\mathrm{sD} 2 \cdot 9) \mathrm{kg} / \mathrm{m}^{2}$. There were no significant differences either between the nutrition students and the control group, with regard to age, BMI and gender distribution, or between the different semesters, with regard to BMI and gender distribution.

\section{Eating behaviour}

The average scores of the eating behaviour aspects, which were assessed with the questionnaire, are detailed in Table 1 together with the ANOVA results.

Nutrition students showed significantly higher dietary restraint than the control students, and dietary restraint decreased significantly in both groups from the beginning of the studies towards the end. With regard to the two subcomponents of dietary restraint, nutrition students had significantly higher scores of both rigid control and flexible control. This did not change significantly between lower and higher semesters. There was no difference between average disinhibition scores, either between nutrition students and the control group or between freshmen and the more advanced students. With regard to orthorexia, a statistical interaction was found. A closer inspection of the means indicates that there was no substantial difference between nutrition students and the control group in the first two semesters. In addition, the tendency of orthorexia remained stable in the control group, whereas it decreased in the nutrition students between the first/second semester and the seventh semester or higher. The food frequency score, which indicates agreement with current dietary recommendations for food selection, did not differ between nutrition students and the control group in the first two semesters. However, the significant statistical interaction indicated that food selection improved in the nutrition students towards the end of their study programme, while it was impaired in the control group.

\section{Discussion}

Students of nutritional science receive a thorough and detailed education in nutrition. Although we did not 
actually measure it, we presume that nutrition students in higher semesters have considerably better nutrition knowledge than students in the first semesters. Indeed, one can barely imagine a population group that has more nutrition knowledge than nutritionists (and students near their final examination) themselves. Thus, this group offers the unique opportunity to examine the effect of maximum or near maximum nutrition education that is possible.

Nutrition students in our study had higher scores of dietary restraint than students from other study programmes. Dietary restraint describes the tendency to restrict food intake in order to lose weight or to maintain weight. Therefore, the conclusion seems justified that weight-control motivation and related eating behaviour is more pronounced in nutrition students than in students of other programmes. The elevated dietary restraint was due to both components of restraint: nutrition students had higher rigid control and higher flexible control of eating behaviour compared to the control group. The higher rigid restraint of the nutrition students might give cause for some concern. However, this heightened rigid control was counterbalanced by a likewise increased flexible control, which reflects a favourable and healthy approach to weight control.

Students from higher semesters had lower scores of dietary restraint than students from the first or second semester, but this did not differ between the nutrition students and the control group. Thus, this decrease of dietary restraint does not seem to be specifically related to the nutritional science curriculum.

In contrast to a sometimes proposed suspicion, there is no indication that students of nutrition have more disturbed or disordered eating patterns in terms of overeating, loss of control or obsessive-compulsive traits, than other students. This conclusion is based on the finding that nutrition students at the beginning of their study programme differ neither in their disinhibition scores nor in their orthorexia scores from other students. For both scales - disinhibition and orthorexia - nutrition students did not have higher scores at the beginning of their studies, and they even decreased their orthorexia scores towards the end of their studies, indicating the development of a less obsessive-compulsive and, therefore, more healthy food choice. This result parallels findings that professionally administered weight loss programmes ${ }^{(32)}$ or healthful dieting behaviours ${ }^{(33)}$ do not increase the risk of developing eating disorders.

While healthy food choices are done in a less obsessive fashion by higher semester nutrition students, their food choices themselves become slightly, but significantly more healthy. This has been in contrast to the control group; there, the food choices became slightly less healthy in higher semesters. Therefore, the increasing knowledge of nutrition students is paralleled by a more healthy food choice and eating behaviour.

The present study has two major limitations. First, the study has been conducted exclusively with students from 
German universities and we have no indication whether the results may be generalised for different countries and different cultural contexts. Secondly, the study used a cross-sectional approach in comparing students from the first two semesters with students from higher semesters. Of course, a longitudinal, prospective study of the same cohorts of students would be necessary to draw conclusions about the development of eating behaviour and related attitudes during the course of the study programme. This cross-sectional study can only offer suggestive support for such changes. In addition, we cannot exclude the possibility that our samples have been too small to detect differences between the groups. However, power calculations according to Cohen ${ }^{(34)}$ yielded that we had a power of 0.99 to detect medium size differences between the nutrition students group and the control group using the present sample sizes. But more subtle differences might have been undetected.

Nevertheless, we think that in summary the conclusion seems justified that: (i) nutrition students, more than other students, tend to restrict their food intake in order to control their body weight, using potentially problematic rigid control behaviours as well as favourable and healthy flexible control behaviours; (ii) nutrition students do not have more disturbed or disordered eating patterns than other students; and (iii) the increasing nutrition knowledge is associated with slightly healthier eating behaviour and food choice.

Taken together, these findings suggest that even massive and extended nutrition education which aims at better nutrition knowledge will have only limited and modest effects on food intake. On the other hand, this study does not support concerns that the increased preoccupation with healthy eating may lead to disordered eating patterns.

\section{Acknowledgement}

No external funding was available for the study. There are no conflicts of interest. A.K. and S.S. developed the basic idea for the present study, participated in the design and interpretation of the study, conducted the study and the statistical analyses of the results, and participated in the preparation of the final manuscript. J.W. participated in the design and interpretation of the study, supervised the implementation of the study and the statistical analyses, and participated in the preparation of the final manuscript. We are very grateful for the support from the lecturers and students of the involved universities for distributing the questionnaires and encouraging students to participate in the study.

\section{References}

1. Commission of the European Communities (2007) White paper on: A Strategy for Europe on Nutrition, Overweight and Obesity related health issues. http://ec.europa.eu/ health/ph_determinants/life_style/nutrition/documents/ nutrition_wp_en.pdf (accessed October 2007).

2. Shepherd R \& Stockley L (1987) Nutrition knowledge, attitudes, and fat consumption. J Am Diet Assoc 87, 615-619.

3. Shepherd R \& Towler G (1992) Nutrition knowledge, attitudes and fat intake: application of the theory of reasoned action. J Hum Nutr Diet 5, 387-397.

4. Aikman SN, Min KE \& Graham D (2006) Food attitudes, eating behavior, and the information underlying food attitudes. Appetite 47, 111-114.

5. Stafleu A, Van Staveren WA, De Graaf C, Burema J \& Hautvast JG (1996) Nutrition knowledge and attitudes towards high-fat foods and low-fat alternatives in three generations of women. Eur J Clin Nutr 50, 33-41.

6. Bellisle F \& Rolland-Cachera MF (2007) Three consecutive (1993, 1995, 1997) surveys of food intake, nutritional attitudes and knowledge, and lifestyle in 1000 French children, aged 9-11 years. J Hum Nutr Diet 20, 241-251.

7. O'Brien G \& Davies M (2007) Nutrition knowledge and body mass index. Health Educ Res 22, 571-575.

8. Shreela VS, Alison DG \& Day RS (2008) Nutrition knowledge predicts eating behavior of all food groups except fruits and vegetables among adults in the Paso del Norte region: Qué Sabrosa Vida. J Nutr Educ Behav 40, 361-368.

9. Wardle J, Parmenter K \& Waller J (2000) Nutrition knowledge and food intake. Appetite 34, 269-275.

10. Crites SL Jr \& Aikman SN (2005) Impact of nutrition knowledge on food evaluations. Eur J Clin Nutr 59, 1191-1200.

11. Bratman S \& Knight D (2000) Health Food Junkies: Orthorexia Nervosa - Overcoming the Obsession with Healthful Eating. New York: Broadway Books.

12. Donini LM, Marsili D, Graziani MP, Imbriale M \& Cannella C (2004) Orthorexia nervosa: a preliminary study with a proposal for diagnosis and an attempt to measure the dimension of the phenomenon. Eat Weight Disord 9 , 151-157.

13. Donini LM, Marsili D, Graziani MP, Imbriale M \& Cannella C (2005) Orthorexia nervosa: validation of a diagnosis questionnaire. Eat Weight Disord 10, e28-e32.

14. Kinzl JF, Hauer K, Traweger C \& Kiefer I (2005) Orthorexia nervosa: eine häufige Essstörung bei Diätassistentinnen? (Orthorexia nervosa: a frequent eating disorder in dieticians?) Ernährungs-Umschau 52, 436-439.

15. Herman CP \& Mack D (1975) Restrained and unrestrained eating. J Pers 43, 647-660.

16. Herman CP \& Polivy J (1975) Anxiety, restraint, and eating behavior. J Abnorm Psychol 84, 66-72.

17. Tuschl RJ (1990) From dietary restraint to binge eating: some theoretical considerations. Appetite 14, 105-109.

18. Wardle J (1980) Dietary restraint and binge eating. Behav Anal Modif 4, 201-209.

19. Wilson GT (2005) Psychological treatment of eating disorders. Annu Rev Clin Psychol 1, 439-465.

20. Hay PJ, Bacaltchuk J \& Stefano S (2004) Psychotherapy for bulimia nervosa and binging. Cochrane Database Syst Rev issue 3, CD000562.

21. Westenhoefer J, Stunkard AJ \& Pudel V (1999) Validation of the flexible and rigid control dimensions of dietary restraint. Int J Eat Disord 26, 53-64.

22. Westenhoefer J (1991) Dietary restraint and disinhibition: is restraint a homogeneous construct? Appetite 16, 45-55.

23. Smith CF, Williamson DA, Bray GA \& Ryan DH (1999) Flexible $v$. rigid dieting strategies: relationship with adverse behavioral outcomes. Appetite 32, 295-305.

24. Westenhoefer J, Broeckmann P, Munch AK \& Pudel V (1994) Cognitive control of eating behaviour and the disinhibition effect. Appetite 23, 27-41. 
25. Westenhoefer J, von Falck B, Stellfeldt A \& Fintelmann S (2004) Behavioural correlates of successful weight reduction over 3 y. Results from the Lean Habits Study. Int J Obes Relat Metab Disord 28, 334-335.

26. American Psychiatric Association (1994) Diagnostic and Statistical Manual of Mental Disorders, 4th ed. Washington, DC: American Psychiatric Association.

27. Pudel V \& Westenhöfer J (1989) Fragebogen zum Eßverhalten. Handanweisung. Göttingen: Hogrefe.

28. Stunkard AJ \& Messick S (1985) The three-factor eating questionnaire to measure dietary restraint, disinhibition and hunger. J Psychosom Res 29, 71-83.

29. Rossiter EM, Wilson GT \& Goldstein L (1989) Bulimia nervosa and dietary restraint. Behav Res Ther 27, 465-468.
30. Hsu LK, Mulliken B, McDonagh B et al. (2002) Binge eating disorder in extreme obesity. Int J Obes Relat Metab Disord 26, 1398-1403.

31. Westenhöfer J (2003) Essen Sie gesund und figurbewußt? Stern issue 12, 207-209.

32. Butryn ML \& Wadden TA (2005) Treatment of overweight in children and adolescents: does dieting increase the risk of eating disorders? Int J Eat Disord 37, 285-293.

33. Neumark-Sztainer D, Wall M, Guo J, Story M, Haines J \& Eisenberg M (2006) Obesity, disordered eating, and eating disorders in a longitudinal study of adolescents: how do dieters fare 5 years later? J Am Diet Assoc 106, 559-568.

34. Cohen J (1977) Statistical Power Analysis for the Behavioral Sciences, revised ed. New York: Academic Press. 